\title{
SURGE IN VENTILATOR-ASSOCIATED PNEUMONIAS AND BLOODSTREAM INFECTIONS IN AN ACADEMIC REFERRAL CENTER CONVERTED TO TREAT COVID-19 PATIENTS
}

\author{
Eric Ochoa-Hein ${ }^{1}$, María F. González-Lara ${ }^{2}$, Martha A. Huertas-Jiménez ${ }^{1}$, Alma R. Chávez-Ríos ${ }^{1}$, \\ Roxana de-Paz-García ${ }^{1}$, Anabel Haro-Osnaya ${ }^{1}$, Ricardo González-GonzálezZ ${ }^{1}$, Blanca S. Cruz-JuáreZ ${ }^{3}$, \\ Thierry Hernández-Gilsoul ${ }^{3}$, Eduardo Rivero-Sigarroa ${ }^{4}$, Alfredo Ponce-de-León ${ }^{3}$, \\ José Sifuentes-Osornio ${ }^{5}$, AND ARTURo Galindo-Fraga ${ }^{1 *}$
}

Departments of ${ }^{1}$ Hospital Epidemiology, ${ }^{2}$ Infectious Diseases, ${ }^{3}$ Emergency and ${ }^{4}$ Intensive Care Unit, and ${ }^{5}$ Directorate of Medicine, Instituto Nacional de Ciencias Médicas y Nutrición Salvador Zubirán, Mexico City, Mexico

\begin{abstract}
Background: Healthcare-associated infections (HAls) are important adverse events that must be prevented. Objective: The objective of the study was to report and study possible changes in HAI rates as well as their causes after the COVID-19 hospital surge capacity response (HSCR) in an academic referral center. Methods: This was a before-after observational study. The Infection Prevention and Control (IPC) program (prospective surveillance, prevention bundles, antibiotic stewardship, continuing education, and feedback) was transiently disrupted after the start of HSCR (March 2020). HAI rates were compared before (January 2019-February 2020) and after (April-July 2020) HSCR, and plausible predisposing factors in affected patients were compared. Results: An increase in the HAl rate from 6.2 to 11.8 cases/1000 patient-days was noted between periods due to increases in ventilator-associated pneumonia and bloodstream infection (BSI) rates. More critically ill patients were admitted during HSCR, and use of invasive devices increased. Prone positioning and infusion of muscle relaxants became commonplace. The nurse-to-patient ratio in the intensive care unit decreased, and $4 \mathrm{~h}$ shifts were introduced to avoid fatigue. The BSI rate decreased after the IPC program with additional measures was reintroduced in May 2020. Conclusions: The strain on the workforce and modifications to the IPC program very possibly underlay the findings. IPC programs continue to be essential during the pandemic. (REV INVEST CLIN. 2021;73(4):210-15)
\end{abstract}

Key words: Healthcare-associated infection. Ventilator-associated pneumonia. Prevention and control. COVID-19.

\section{INTRODUCTION}

Healthcare-associated infections (HAls) are the most frequent adverse events related to patient care $^{1}$, but they can be avoided when adhering to prevention practices $^{2,3}$. Use of prevention bundles ${ }^{4}$ in our hospital led to a gradual improvement in the prevention of ventilator-associated pneumonias (VAPs) ${ }^{5}$ and bloodstream infections (BSIs) (not published), achieving nearly zero rates in months previous to the severe
*Corresponding author:

Arturo Galindo-Fraga

E-mail: arturo.galindof@incmnsz.mx
Received for publication: 05-03-2021

Approved for publication: 12-05-2021

DOI: $10.24875 / R I C .21000130$

0034-8376 / (c) 2021 Revista de Investigación Clínica. Published by Permanyer. This is an open access article under the CC BY-NC-ND license (http://creativecommons.org/licenses/by-nc-nd/4.0/). 
acute respiratory syndrome coronavirus 2 pandemic. Full COVID-19 hospital surge capacity response (HSCR) started on March 16, 2020, and with it came the following changes in clinical workflow: (1) the nurse-to-patient ratio in the intensive care unit (ICU) declined from $1: 1$ to $1: 2$ during HSCR due to bed expansion; ( 2 ) $<10 \%$ of staff was specialized in critical patient care; (3) $4 \mathrm{~h}$ shifts were introduced to avoid fatigue related to the use of personal protective equipment; and (4) prone positioning and infusion of muscle relaxants were fully implemented during $\mathrm{HSCR}$, and daily awakening protocols were reduced as a consequence. In addition, epidemiological surveillance rounds were temporarily restricted by heads of different hospital areas in an attempt to lower overall risk of contagion among staff.

It was unknown if these changes had an impact on HAI rates. Therefore, the objective of this research was to calculate HAl rates before and after HSCR, as well as to study the most likely causes of any differences.

\section{METHODS}

A before-after observational study was conducted. Active search and report of HAls as well as patient predisposing factors are routinely done in a prospective, standardized manner and did not undergo any changes during the study period. Mainly due to this reason, the institutional review board granted a waiver for informed consent; furthermore, the study was deemed to pose no risk to patients due to the use of deidentified data in the database.

Our institutional Infection Prevention and Control (IPC) program relies on the following: (1) daily prospective surveillance, (2) HAl prevention bundles, (3) antibiotic stewardship, (4) continuing education, and (5) performance feedback on a monthly basis. Objective evidence on the conduct of these activities is routinely recorded on standardized sheets and reported monthly, as per hospital policies.

Starting in May 2020, additional IPC measures instituted were (1) retraining in prevention bundles, (2) retraining in safe central venous catheter insertion practices, (3) halting of double gloving, (4) emphasis on hand hygiene, and (5) weekly meetings between hospital authorities and heads of clinical areas.
HAls were identified in all hospitalization areas (emergency department, ICU, accessory critical area, and hospital wards) and defined according to the NHSN standardized criteria current in 2019 and $2020^{6}$. HAI events and the corresponding denominator data were recorded daily. Monthly HAI rates were calculated dividing the number of events by the number of patient-days and then multiplying by 1000; patientdays was used to simplify comparisons between different types of HAls (rates adjusted to device-days and patient-days gave similar trends).

The following variables were compared among patients affected by HAls: sex, age, length of stay before diagnosis of HAl, hospital area where HAl was identified, rate of in-hospital death, risk factors for hospital-acquired pneumonias and VAPs (endotracheal intubation, tracheostomy, use of humidifier, use of feeding tubes, use of proton-pump inhibitors, or $\mathrm{H} 2$ receptor antagonists), risk factors for BSIs (use of any type of venous or arterial catheter, parenteral nutrition), risk factors for catheter-associated urinary tract infection (use of urinary catheter), and risk factors for Clostridioides difficile infection (previous use of antibiotics, proton-pump inhibitors, and $\mathrm{H} 2$ receptor antagonists). Absolute and relative frequencies were used to summarize data.

Two time periods were compared: before HSCR (January 2019-February 2020) and during HSCR (AprilJuly 2020). March 2020 was left out due to active HSCR. Gradual resumption of routine hospital activities began in July 2020 .

\section{Statistical Analysis}

Statistical analysis by the Chi-square test or Fisher's exact test (for categorical variables) or the Wilcoxon rank-sum test (for numerical variables) was done to contrast differences between the two time periods, considering a $p$ cutoff value of $\leq 0.05$ as statistically significant. Stata ${ }^{\odot}$ version 14.0 (StataCorp, College Station, TX, USA) was used.

\section{RESULTS}

Before HSCR, 449 HAls in 72,832 patient-days were identified $(\mathrm{HAI}$ rate $=6.2 /$ per 1000 patient-days). During HSCR, 170 HAls in 14,372 patient-days occurred (HAl rate $=11.8$ cases per 1000 patient-days). 
Figure 1. Healthcare-associated infection rates stratified by type of infection. Catheter-associated urinary tract infection and surgical site infection were left out for clarity; no changes were noted in rates of the former and no surgeries related to nonCOVID-19 conditions were done during hospital surge capacity response.

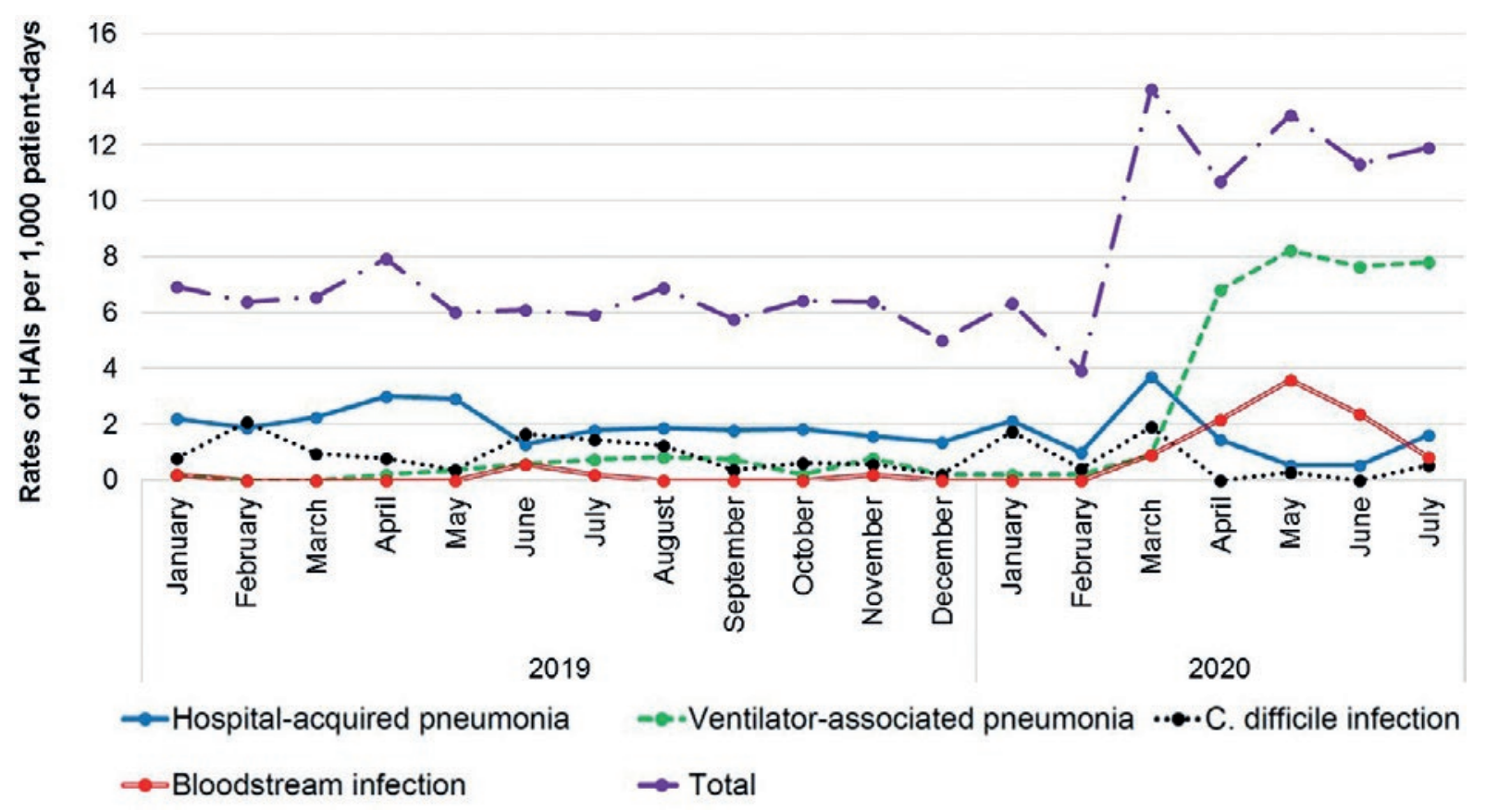

The increase in the total HAl rate during HSCR was due to increases in VAP and BSI rates (Fig. 1).

A greater proportion of critically ill patients was admitted during HSCR, leading to an increase in the prevalence of risk factors related to insertion and use of invasive devices (Table 1 ).

Due to the workflow modifications during HSCR mentioned above, surveillance and estimation of adherence to the various measures of the IPC program were non-existent during HSCR.

The types of microorganisms causing HAls differed between the two periods (Table 1). During HSCR, an increase in the proportion of Gram-negative bacilli and fungi was noted; in contrast, cases of $C$. difficile infection diminished.

\section{DISCUSSION}

An increase in BSI and VAP rates in our hospital was temporally associated with the interruption of our IPC program and changes in work standards due to HSCR.
Our findings are in agreement with another study that reported a notorious increase in the BSI rate in COVID-19 patients, mostly due to Gram-negative bacteria $^{7}$; among the causes, a higher number of critical patients admitted to strained ICUs, reduced staff-topatient ratios, and increased length of stay of patients were found. As noticed in that report, we also observed a reduction in our BSI rate after adoption of preventive actions. Although we are not able to provide a statistical value to this observation due to the limited HSCR time period during which BSI rates increased, there was a notorious reduction after the IPC program was resumed.

Regarding the VAP rate, our findings were similar to those of another study ${ }^{8}$ : VAP in COVID-19 patients was a very frequent occurrence when mechanical ventilation was required. The rise in the endotracheal intubation rate related to the pandemic was a contributory factor ${ }^{5}$; however, prone positioning, use of muscle relaxants, a decreased rate of daily awakening protocols, and decreased surveillance of HAls could also be associated. Of the potential associated factors mentioned previously, only resumption of surveillance was possible since modification of the others 
Table 1. Comparison of patient characteristics, risk factors, and microorganisms isolated from healthcare-associated infections before and during HSCR

\begin{tabular}{|c|c|c|c|}
\hline Variable & $\begin{array}{c}\text { Before HSCR } \\
n(\%)^{a}\end{array}$ & $\begin{array}{c}\text { During HSCR } \\
n(\%)^{\mathrm{a}}\end{array}$ & $\mathrm{p}$ \\
\hline HAl rate ( $\times 1000$ patient-days $)$ & 6.2 & 11.8 & 0.023 \\
\hline Male sex & $213(47.4)$ & $117(68.8)$ & $<0.001$ \\
\hline Age, years (median, IQR) & $53(41-68)$ & $53(43-60)$ & 0.150 \\
\hline LoS before HAI, days (median, IQR) & $13(7-23)$ & $10.5(8-17)$ & 0.010 \\
\hline In-hospital death & $24(5.3)$ & $55(32.4)$ & $<0.001$ \\
\hline \multicolumn{4}{|l|}{ Types of HAls } \\
\hline VAP & $45(10.0)$ & $93(54.7)$ & $<0.001$ \\
\hline Hospital-acquired pneumonia & $121(26.9)$ & $31(18.2)$ & 0.025 \\
\hline BSI & $6(1.3)$ & $35(20.6)$ & $<0.001$ \\
\hline Candidemia & $0(0)$ & $14(8.2)$ & $<0.001$ \\
\hline $\begin{array}{l}\text { Catheter-associated urinary } \\
\text { tract infection }\end{array}$ & $37(8.3)$ & $6(3.5)$ & 0.039 \\
\hline Surgical site infection & $113(25.2)$ & $0(0) b$ & NA \\
\hline C. difficile infection & $68(15.2)$ & $3(1.8)$ & $<0.001$ \\
\hline Other & $59(13.1)$ & $2(1.2)$ & $<0.001$ \\
\hline \multicolumn{4}{|l|}{ Risk factors for various HAls } \\
\hline Arterial catheter & $2(0.4)$ & $52(30.6)$ & $<0.001$ \\
\hline Hemodialysis catheter & $11(2.4)$ & $12(7.1)$ & 0.007 \\
\hline Central venous catheter & $306(68.2)$ & $158(92.9)$ & $<0.001$ \\
\hline Venous peripheral catheter & $232(51.7)$ & $86(50.6)$ & 0.806 \\
\hline Parenteral nutrition & $3(0.7)$ & $3(1.8)$ & 0.354 \\
\hline Endotracheal intubation & $51(11.4)$ & $154(90.6)$ & $<0.001$ \\
\hline $\begin{array}{l}\text { Time from endotracheal } \\
\text { intubation to VAP, days } \\
\text { (median, IQR) }\end{array}$ & $9(6-14)$ & $10.5(8-16)$ & 0.087 \\
\hline Use of humidifier & $19(4.2)$ & $5(2.9)$ & 0.458 \\
\hline Tracheostomy & $11(2.4)$ & $5(2.9)$ & 0.778 \\
\hline Nasogastric tube & $5(1.1)$ & $4(2.4)$ & 0.268 \\
\hline Nasojejunal tube & $0(0)$ & $27(15.9)$ & $<0.001$ \\
\hline $\begin{array}{l}\text { Use of PPI or } \mathrm{H} 2 \text { receptor } \\
\text { antagonists }\end{array}$ & $311(69.3)$ & $116(68.2)$ & 0.806 \\
\hline Urinary catheter & $186(41.4)$ & $155(91.2)$ & $<0.001$ \\
\hline Use of antibiotics before $\mathrm{HAI}$ & $381(84.9)$ & $121(71.2)$ & $<0.001$ \\
\hline \multicolumn{4}{|c|}{ Hospital area where HAI was identified } \\
\hline Wards & $365(81.3)$ & $9(5.3)$ & $<0.001$ \\
\hline Emergency department & $44(9.8)$ & $108(63.5)$ & \\
\hline ICU & $39(8.7)$ & $38(22.4)$ & \\
\hline Accessory critical area & NA & $15(8.8)$ & \\
\hline Other area & $1(0.2)$ & $0(0)$ & \\
\hline
\end{tabular}


Table 1. Comparison of patient characteristics, risk factors, and microorganisms isolated from healthcare-associated infections before and during HSCR (continued)

\begin{tabular}{|c|c|c|c|}
\hline Variable & $\begin{array}{c}\text { Before HSCR } \\
n(\%)^{\mathrm{a}}\end{array}$ & $\begin{array}{c}\text { During HSCR } \\
n(\%)^{\mathrm{a}}\end{array}$ & $\mathrm{p}$ \\
\hline \multicolumn{4}{|c|}{ Hospital area where HAl was identified } \\
\hline Microorganisms isolated & 288 & 207 & \\
\hline Gram-negative bacilli & $140(48.6)$ & $141(68.1)$ & $<0.001$ \\
\hline Enterobacter cloacae & 4 & 33 & \\
\hline Escherichia coli & 34 & 22 & \\
\hline Klebsiella pneumoniae & 16 & 18 & \\
\hline Other Enterobacteriaceae & 28 & 28 & \\
\hline Pseudomonas aeruginosa & 27 & 24 & \\
\hline $\begin{array}{l}\text { Other non-fermenting } \\
\text { Gram-negative bacilli }\end{array}$ & 31 & 16 & \\
\hline Gram-positive cocci & $42(14.6)$ & $27(13.0)$ & 0.624 \\
\hline Enterococci & 24 & 5 & \\
\hline Staphylococcus aureus & 9 & 9 & \\
\hline Coagulase-negative staphylococci & 1 & 9 & \\
\hline Other cocci & 8 & 4 & \\
\hline Fungi & $23(8.0)$ & $35(17.0)$ & 0.002 \\
\hline Candida albicans & 9 & 9 & \\
\hline Non-albicans Candida spp. & 6 & 14 & \\
\hline Aspergillus spp. & 5 & 9 & \\
\hline Other fungi & 3 & 3 & \\
\hline C. difficile & $68(23.6)$ & $3(1.4)$ & $<0.001$ \\
\hline Other microorganism & $15(5.2)$ & $1(0.5)$ & 0.003 \\
\hline \multicolumn{4}{|c|}{ Resistant microorganisms of epidemiological importance } \\
\hline ESBL producers & $4 / 8(50.0)$ & $12 / 29(41.4)$ & 0.705 \\
\hline AmpC producers & $6 / 14(42.9)$ & $52 / 82(63.4)$ & 0.146 \\
\hline $\begin{array}{l}\text { Carbapenem-resistant } \\
\text { Enterobacteriaceae }\end{array}$ & $2 / 12(16.7)$ & $9 / 79(11.4)$ & 0.635 \\
\hline Methicillin-resistant S. aureus & $2 / 6(33.3)$ & $0 / 5(0)$ & 0.455 \\
\hline Multidrug-resistant $P$. aeruginosa & $5 / 7(71.4)$ & $2 / 21(9.5)$ & 0.004 \\
\hline $\begin{array}{l}\text { Carbapenem-resistant } \\
\text { Acinetobacter baumannii }\end{array}$ & 4/4 (100) & - & NA \\
\hline Azole-resistant Candida species & - & $8 / 13(61.5)$ & NA \\
\hline
\end{tabular}

aUnless otherwise stated.

bNon-COVID-19 surgical procedures were halted during HSCR.

HSCR: hospital surge capacity response; HAl: healthcare-associated infection; IQR: interquartile range; LoS: length of stay; VAP: ventilatorassociated pneumonia; BSI: bloodstream infection; PPI: proton-pump inhibitor; NA: not applicable; ESBL: extended-spectrum beta-lactamase; AmpC: ampC beta-lactamase. ICU: intensive care unit, C. difficile: Clostridioides difficile.

was unfortunately restricted to patients without severe disease. This could explain the lack of reduction in VAP rates.
The rates of hospital-acquired pneumonia in wards remained stable, possibly due to the admission of nonintubated and less severely ill patients in such areas. 
Finally, two circumstances that may account for reduced rates of $C$. difficile infection were (1) not admitting patients with active infection and (2) increased adherence of hand hygiene and contact precautions by staff 9 .

Pending further studies, the present one suggests that HAI preventive tasks may be compromised during the COVID-19 pandemic. A previous survey found that the majority of the personnel dedicated to IPC duties spent most of the time responding to the COVID-19 emergency, undermining important activities such as surveillance of adherence to hand hygiene, chlorhexidine bathing, antimicrobial stewardship programs, and provider feedback ${ }^{10}$.

We acknowledge limitations. Because interruption of the IPC program coincided with changes in workflow and in medical procedures (especially prone positioning), we were not able to estimate the relative contribution of each separate event to the increase in HAls during HSCR. However, the decrease in BSI rates after resumption of the IPC program in May 2020 (and accompanying additional measures specific to the prevention of BSIs) plus no further changes in the other likely associated factors previously mentioned, support the observation that interruption of the IPC program was very possibly related to the surge in HAls. Although the use of dexamethasone could be theoretically related to increases in HAl rates elsewhere, we consider this highly unlikely in our setting since dexamethasone use was established after June 30,2020 ; therefore, this variable was not analyzed in our study.

In summary, an increase in the incidence of VAPs and BSIs was noted during HSCR in a COVID-19 setting. Resumption of prevention activities allowed a reduction of BSI rates. IPC programs must remain an essential activity during the COVID-19 pandemic.

\section{REFERENCES}

1. Report on the Burden of Endemic Health Care-associated Infection Worldwide. Geneva: World Health Organization; 2011. Available from: https://www.apps.who.int/iris/bitstream/handle/10665/80135/9789241501507 eng.pdf;jsessionid=8B9 1D43D5D4D956A28728BBA6D40E7C 1 ? sequence $=1$. [Last accessed on 2020 Oct 02].

2. Centers for Disease Control and Prevention. Antibiotic Resistance and Patient Safety Portal. Atlanta, Georgia Centers for Disease Control and Prevention; 2020. Available from: https:// www.arpsp.cdc.gov/profile/infections. [Last accessed on 2020 Oct 02].

3. Centers for Disease Control and Prevention. Healthcare-associated Infections. Atlanta, Georgia: Centers for Disease Control and Prevention; 2017. Available from: https://www.cdc.gov/ hai/data/archive/data-summary-assessing-progress.html. [Last accessed on 2020 Oct 02].

4. Manual for Implementation of Action Bundles for Prevention and Surveillance of Healthcare-associated Infections. Health Secretariat, Mexico; 2019. Available from: http://www.calidad.salud. gob.mx/site/editorial/docs/manual_IAAS.pdf. [Last accessed on 2020 Oct 02].

5. Ochoa-Hein E, Choi SJ, Gómez-Santillán JA, Oyervides-Alvarado JA, Galindo-Fraga A, Rivero-Sigarroa E, et al. Near-zero ventilator-associated pneumonia rates after implementation of a multimodal preventive strategy in a Mexican hospital. Am J Infect Control. 2020;48:446-7.

6. Centers for Disease Control and Prevention. National Healthcare Safety Network (NHSN) Patient Safety Component Manual. Atlanta, Georgia: Centers for Disease Control and Prevention; 2020. Available from: https://www.cdc.gov/nhsn/pdfs/validation/2020/pcsmanual_2020-508.pdf. [Last accessed on 2020 Oct 02].

7. Sturdy A, Basarab M, Cotter M, Hager K, Shakespeare D, Shah $\mathrm{N}$, et al. Severe COVID-19 and healthcare-associated infections on the ICU: time to remember the basics? J Hosp Infect. 2020:105:593-5

8. Zhou F, Yu T, Du R, Fan G, Liu Y, Liu Z, et al. Clinical course and risk factors for mortality of adult inpatients with COVID-19 in Wuhan, China: a retrospective cohort study. Lancet. 2020; 395:1054-62.

9. Ochoa-Hein E, Rajme-López S, Rodríguez-Aldama JC, HuertasJiménez MA, Chávez-Ríos AR, de Paz-García R, et al. Substantial reduction of healthcare facility-onset Clostridioides difficile infection ( $\mathrm{HO}-\mathrm{CDI}$ ) rates after conversion of a hospital for exclusive treatment of COVID-19 patients. Am J Infect Control. 2020;2020:31044-0.

10. Stevens MP, Doll M, Pryor R, Godbout E, Cooper K, Bearman G. Impact of COVID-19 on traditional healthcare-associated infection prevention efforts. Infect Control Hosp Epidemiol. 2020; 41:946-7. 